\title{
Diagnosis of early myocardial damage in asymptomatic diabetic patients using 2D speckle tracking echocardiography
}

\author{
Fatmir Ferati ${ }^{1 *}$ \\ Mentor Karemani² \\ Anida Ferat ${ }^{3}$ \\ Ardian Preshova ${ }^{3}$ \\ Nexhbedin Karemani ${ }^{1}$ \\ 'University Hospital Tetovo, \\ Tetovo, Republic of \\ Macedonia \\ ${ }^{2}$ Medicus Lux, Tetovo, \\ Republic of Macedonia \\ ${ }^{3}$ Med-Artis, Tetovo, Republic \\ of Macedonia
}

KEYWORDS: diabetes mellitus, 2D strain, longitudinal strain, radial strain, circumferential strain, time to peak. CITATION: Cardiol Croat. 2015;10(3-4):60. | DOI: http://dx.doi.org/10.15836/ccar.2015.60

ORCID: Fatmir Ferati, http://orcid.org/0000-0001-8189-316X

*ADDRESS FOR CORRESPONDENCE: Fatmir Ferati, Spitali Klinik Tetovë, Memet Pashe Derala bb, 1200 Tetovi, Republika Makedonija. Phone: +389-70-224138. E-mail: fatmir_ferati@yahoo.com

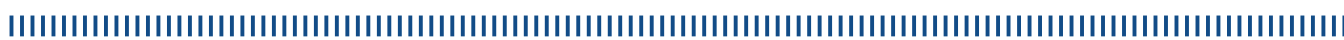
The aim of this paper is the analysis of 2D strain values and other values of LV such as: $\mathrm{dV} / \mathrm{dT}$ among non-symptomatic diabetic patients (without documented heart disease) and the control group. ${ }^{1-4}$

One hundred patients with non-symptomatic diabetes mellitus were analyzed (55 males and 45 females) with an average age of 56 years ( $56 \pm 20$ years).

In the group of people without a verified disease, 50 individuals have been chosen (26 males and 24 females), with an average age of 55.3 years old $(55.3 \pm 17)$

\section{RESULTS:}

1. At parasternal views, there is a decrease of 2D strain in patients with diabetes, more emphasized in the MV level while at the PM level, these changes are less emphasized.

2. Decrease of longitudinal strain values (LS) at the $4 \mathrm{C}$ and $3 \mathrm{C}$, bellow the normal values for the $\mathrm{LC}$ are registered. A decrease of RS values is registered in our study but they are within normal values for RS.Considering these two facts, it can be concluded that LS is the main damage which occurs and characterizes non-symptomatic diabetic people.

3. On the basis of these data, it may be stated that the value of under $18 \%$ of LS can be taken as the dominant value which is recorded in this study in patients with diabetes.

4. In relation to the duration of diabetes, a significant difference is recorded in 2D strain between patients with diabetes in relation to the duration of the disease.

5. The changes in LC are the first recorded changes in patients with diabetes.

6. In patients with diabetes and complications, decrease in values of 2D strain appear, which are more emphasized in LS.

7. A decrease in values of strain is registered in patients who were on therapy with insulin, unlike those without.

8. There is decrease of $\mathrm{dV} / \mathrm{dT}$ in patients with diabetes

9. Extension of $\mathrm{T} 2 \mathrm{P}$ values in patients with diabetes is registred

10. A post systolic shortening phenomenon (PSS) is recorded at patients with diabetes compared to those without diabetes,

11. Increase of the left ventricular mass in patients with diabetes is recorded.

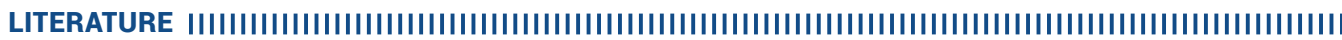

1. Shivu GN, Abozguia K, Phan TT, Ahmed I, Weaver RA, Wagenmakers A. Increased left ventricular twist as an early manifestation of diabetic cardiomyopathy in patients with uncomplicated type 1 diabetes. Heart. 2009;95 (Suppl 1);21.

2. Poirier P, Bogaty P, Garneau C, Marois L, Dumesnil JG. Diastolic dysfunction in normotensive men with well-controlled type 2 diabetes: importance of maneuvers in echocardiographic screening for preclinical diabetic cardiomyopathy. Diabetes Care. 2001;24:5-10. DOI: http://dx.doi.org/10.2337/diacare.24.1.5

3. Fang ZY, Prins JB, Marwick TH. Diabetic cardiomyopathy: evidence, mechanisms, and therapeutic implications. Endocr Rev. 2004;25:543-67. DOI: http://dx.doi.org/10.1210/er.2003-0012

4. Nakai H, Takeuchi M, Nishikage T, Lang RM, Otsuji Y. Subclinical left ventricular dysfunction in asymptomatic diabetic patients assessed by two-dimensional speckle tracking echocardiography: correlation with diabetic duration. Eur J Echocardiogr. 2009;10(8):926-32 DOI: http://dx.doi.org/10.1093/ejechocard/jep097 